Article

\title{
SUAS Based Multispectral Imagery for Monitoring Wetland Inundation and Vegetation
}

\author{
Dustin Dehm ${ }^{1}$, Richard Becker ${ }^{1,2, *}$, and Alexandra Godre ${ }^{1}$ \\ 1 University of Toledo, Department of Environmental Sciences, Toledo, OH 43606 USA \\ 2 University of Toledo, Lake Erie Center, Toledo, OH 43606 USA \\ * Correspondence: Richard.Becker@utoledo.edu; Tel.: (419)-530-4571
}

\begin{abstract}
Mapping short-term wetland vegetation and water storage changes is valuable for monitoring the biogeochemical processes of wetland systems. Old Woman Creek National Estuarine Research Reserve is a dynamic freshwater estuary which experiences intermittent changes in water level over the course of a year. Small unmanned aerial systems (sUAS) are useful tools in monitoring changes as they are rapidly deployed, repeatable, and high-resolution. In this study, commercial quadcopters were paired with a red/green/near-infrared MAPIR Survey $3 \mathrm{~W}$ camera to produce normalized difference vegetation index (NDVI) and normalized difference water index (NDWI) maps to observe short-term changes at OWC. Orthomosaics were produced for flights on 8 days throughout 2018 and early 2019. The orthomosaics were calibrated to bottom-of-atmosphere reflectance using the Empirical Line Correction method, after which NDVI and NDWI maps were created. The NDVI pixel values were used to generate maps of vegetation extent showing density changes over time. Identifying dominant vegetation in these maps allowed for the application of the National Estuarine Reserve System (NERRS) Classification Codes to zones of interest. NDWI provided water extent at different water levels and when paired with LiDAR and bathymetric data yielded water volume and residence time estimates.
\end{abstract}

Keywords: sUAS; UAV; drone; multispectral; wetland; NDVI; NDWI; remote sensing

\section{Introduction}

Wetland systems serve as valuable water resources which not only filter water from upland areas but are a habitat for many species of plants and animals and serve as a recreational nature area for the community. Currently, wetland monitoring methods by remote sensing are mainly satellite and aerial based platforms. Satellite systems such as the European Space Agency's [1] Sentinel-2 offer frequent revisits every 2-5 days at a 10-meter pixel resolution [2], while aerial platforms such as the National Agriculture Imagery Program (NAIP) have higher resolution than satellite imagery [3], but are only flown every 2-3 years due to the costs of flights. Wetlands are also monitored at ground level via line-of-sight observations or point measurements by foot or by boat.

Old Woman Creek (OWC) (Figure 1a) was selected as the study site for this method because of its dynamic nature and its local significance as the only freshwater National Estuarine Research Reserve on Lake Erie [4]. OWC is the outlet for about $70 \mathrm{~km}^{2}$ of mostly agricultural land and is a nutrient sink for agricultural runoff [5]. The defining characteristic of OWC is the barrier beach on the northern side of the estuary which connects the wetland to Lake Erie and classifies the wetland as a barred drowned river-mouth [6] (Figure 1b). This barrier beach is seasonally breached in the winter, late spring, and after strong storm events [4]. The beach has also been breached artificially by the local community when high water levels were overtopping and threatening the integrity of riprap on a side channel to the east, resulting in about a one-meter drop in water level over a 24-hour period when the water levels were high, drastically changing the habitats in the main basin. The 
wetland's deepest point is the main channel as it passes under the Route 6 bridge to the north which can be as deep as 3.6 meters, but most of the main basin is sub-meter in depth [7].

Old Woman Creek National Estuarine Research Reserve

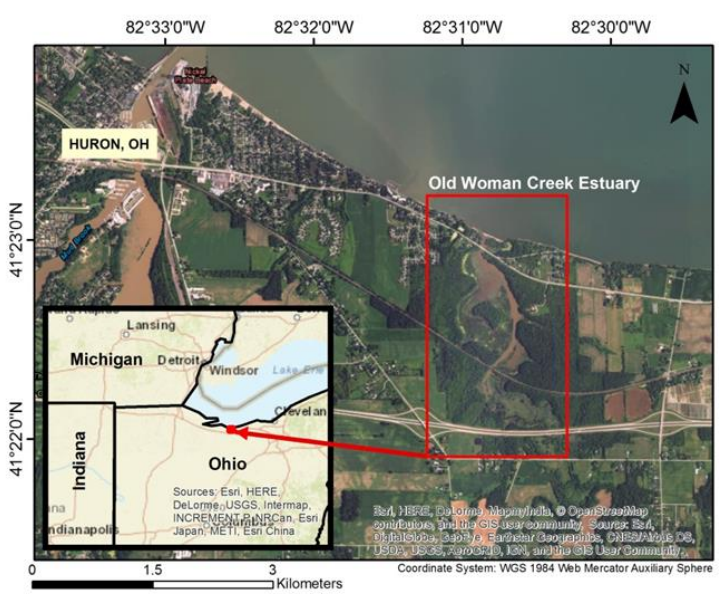

(a)

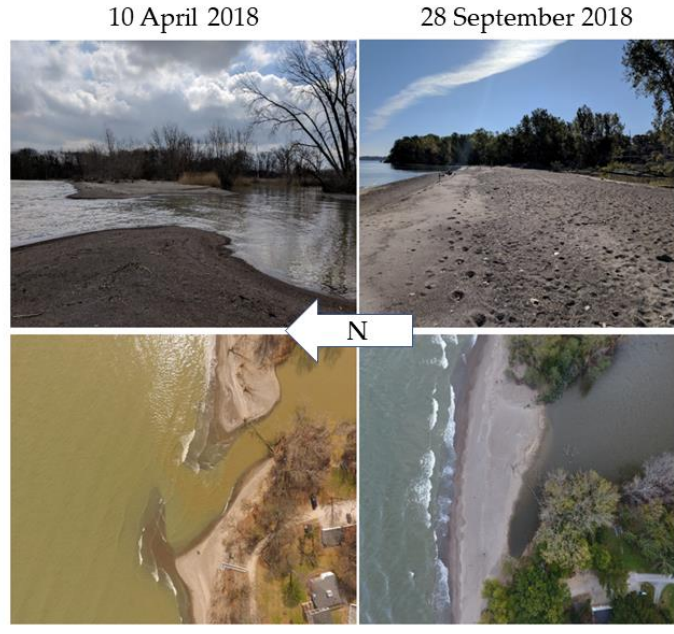

(b)

Figure 1. (a) Study Site; (b) Barrier beach on the north side of OWC connecting to Lake Erie

These rapid changes are not captured well using current remote sensing methods. Satellite imagery does not do well at defining smaller areas of inundation and distinguishing the shoreline due to pixel mixing and revisit scenes which are often rendered ineffective by cloud cover [8]. Aerial imagery is not acquired frequently enough here to capture any seasonal change but can be useful as a snapshot of long-term habitat changes. SUAS offer a high temporal and spatial resolution solution which is of similar or better quality to aerial imagery, with higher revisit times [9]. The focus of this study is the effectiveness of lightweight low-cost sUAS based multispectral cameras in mapping short-term wetland emergent vegetation and water inundation changes over time [10].

\section{Materials and Methods}

This study used two commercial Dà-Jiāng Innovations [11] (https://www.dji.com) Phantom unmanned aerial vehicles (UAV) as flight platforms. The Phantom 3 Professional and the Phantom 4 Standard quadcopter models were affordable and provided flexibility in takeoff and landing sites. The payload capacity of both UAVs was enough to carry the 76g MAPIR Survey $3 \mathrm{~W}$ camera with approximately 25 minutes of flight time. The MAPIR Survey $3 \mathrm{~W}$ (https://www.mapir.camera) Red/Green/Near-Infrared (RGN) Sony Exmor R IMX117 12 MegaPixel (MP) camera employs a complementary metal-oxide semiconductor (CMOS) chip and has bands at 660 nanometers $(\mathrm{nm})$, $550 \mathrm{~nm}$, and $850 \mathrm{~nm}$. The CMOS sensor exposes a line of pixels at a time to detect photons, and transfers the information while the next line is exposed [12]. The CMOS sensor is cheaper and uses lower battery power than the traditional charged-couple device (CCD) array, and recent advances in CMOS technology makes them ideal for affordable sUAS applications [12]. The Phantom 3 and Phantom 4 are also equipped with a 12.4 MP red/green/blue (RGB) camera.

All flights were conducted in accordance with the Federal Aviation Administration (FAA) Part 107 regulations by licensed remote pilots [13]. Visual observers were also used to keep visual contact of the UAV during flights. Flights were scheduled between 9AM and 11AM at OWC to avoid excessive pedestrian traffic in the reserve and to keep incident sun angles consistent throughout scenes. Flights were programmed and flown using the automated flight software DroneDeploy (https://www.dronedeploy.com/). Flights were set up with $65-70 \%$ side and $75 \%$ front overlap between RGB images at 120-meter altitude above ground level [14] with flight speeds of approximately 14-meters per second. The Survey $3 \mathrm{~W}$ RGN camera was set to acquire images at 
either 1.5 seconds per photo for JPG files or 2.75 seconds per photo for RAW+JPG acquisition [15] via its built-in timer software and had greater side and front overlap than the Phantom RGB photos.

Five ground control points (GCP) were used to increase the orthomosaic's vertical and horizontal accuracy. Three of the GCPs were National Geodetic Survey (NGS) benchmarks located in the study area upon which $60 \times 60$-centimeter plywood contrasted boards were placed which could be easily seen in images [16]. One additional GCP was created via a laser level survey using one of the NGS benchmarks as a base station. Another artificial GCP was created by identifying a feature in both a LiDAR digital elevation map (DEM) and imagery and setting a higher level of error [17]. For calibration purposes, a Spectralon board of 99\% reflectance was set out before each flight. The Spectralon board and other homogeneous and spectrally stable surfaces were measured with an ASD FieldSpec Pro spectrometer several times throughout the study as calibration and validation targets $[18,19]$. ASD measurements were acquired using an 8-degree foreoptic. White references were taken 10 times from approximately a meter above a 99\% reflectance Spectralon board [20]. The ratio of upwelling to downwelling irradiance results in a reflectance value. The surfaces used to calibrate scenes were selected because of their spatial and spectral stability over time so they could be used across multiple scenes [18, 19]. Examples of calibration surfaces include the Spectralon board, roads, sand, parking lots, the drone carrying case, and the university truck.

Agisoft Photoscan (https://www.agisoft.com) structure from motion (SfM) software was used to create the orthomosaics from flight images [21]. The SfM software identifies common tie points between image overlap and uses each image's geo-location and UAV orientation to stitch images together without geometric distortion as an orthomosaic [22, 23]. A modified SfM workflow from the U.S. Geological Survey (USGS) National Unmanned Aircraft Systems Project Office [24] was used to process the flight imagery [24] (Figure 2).

\section{Agisoft Photoscan Workflow}

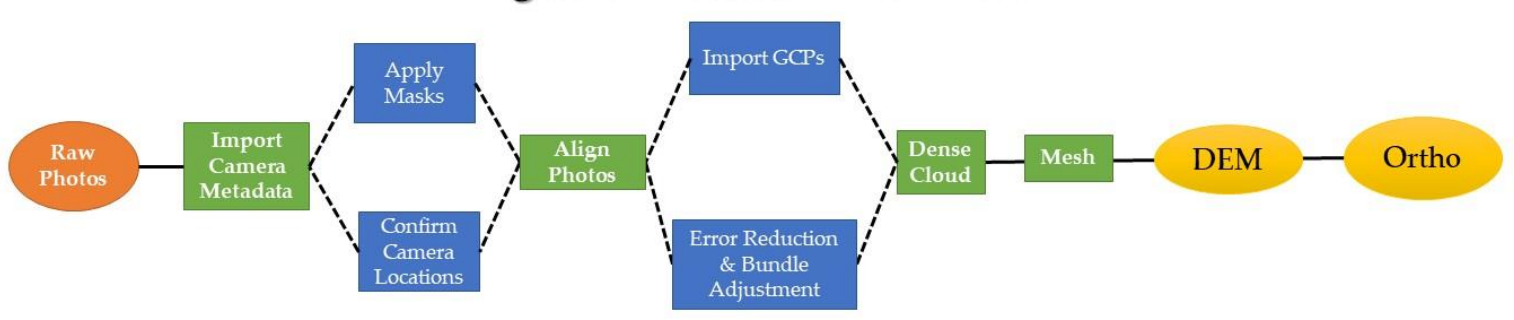

Figure 2. Agisoft Photoscan workflow

After images were imported into Agisoft Photoscan masks were applied to areas of sun-glint, saturation, and distortion. The photos were then aligned using key points and tie points, which are significant features identified in multiple images [21, 25]. Aligned points create a sparse cloud upon which the GCPs were imported and aligned, and an error reduction and bundle adjustment was run to eliminate tie points with low accuracy [26]. Once only high confidence tie points remained, a dense cloud was created from the other pixels in each image upon which a mesh was created. From the mesh, a DEM and orthomosaic were created and exported for calibration.

The uncalibrated orthomosaics were imported into Environment for Visualizing Images (ENVI) (Exelis Visual Information Solutions, Boulder, Colorado) software for calibration of digital numbers (DN) to bottom-of-atmosphere reflectance using the empirical line correction (ELM) method [27]. The ELM equation:

\section{$D N_{b}=p(\lambda) \times A_{b}+B_{b}$,}


takes into account transmittance $\left(\mathrm{Ab}_{\mathrm{b}}\right)$, atmospheric path radiance $\left(\mathrm{B}_{\mathrm{b}}\right)$, and reflectance at certain wavelengths $(\boldsymbol{p}(\lambda))$ as it pertains to the digital number $\left(\mathrm{DN}_{\mathrm{b}}\right)$ [28]. The $\mathrm{DNs}$ were calibrated to reflectance using surfaces of known spectral properties within the scene which were measured using the ASD FieldSpec Pro spectrometer. Reflectance values calculated from both a bright and dark target were applied to the images. In any given mosaic, two to five surfaces were used as calibration targets, while two to four surfaces were reserved as validation targets. Calibration also included geospatial corrections from errors in the orthomosaic process and camera locations. Scenes were georeferenced in relation to each other to ensure habitat extent changes were accurate.

The calibrated scenes were used to calculate spectral indices. NDVI is the ratio of red light absorbed by plants for use in photosynthesis to the amount of near-infrared reflected by the cellular wall structure of healthy plants, and was developed to exploit the spectral properties of vegetation $[12,29]$. NDVI values fall between -1 and 1 , where values closer to 1 represent more dense vegetation and values below 0 represent non-vegetation surfaces such as water, concrete, sand, etc. The NDVI equation is:

\section{$\mathrm{NDVI}=\mathrm{B}_{3}-\mathrm{B}_{1} / \mathrm{B}_{3}+\mathrm{B}_{1}$}

where $B_{3}$ is the reflectance at 880 -nanometers and $B_{1}$ is the reflectance at 660 -nanometers. NDVI values were classified as vegetation and non-vegetation. Classifications followed the USGS classification scheme of NDVI where values below 0.2 are no vegetation, $0.2-0.5$ is sparse vegetation, and 0.6-0.9 is dense vegetation [30]. A pixel was considered vegetation in the orthomosaics if NDVI exceeded 0.2. Extents were calculated for an area of interest at OWC across scenes from different times of the year to calculate emergent vegetation changes. Various dominant emergent vegetation types were identified using their visual and spectral properties. Volunteers and OWC staff conducting wildlife habitat surveys provided their data from similar time periods within days of the flight surveys to identify dominant species in each polygon. An area of dominant vegetation was then quantified by extent polygons over spectrally and texturally similar areas validated by the ground vegetation surveys. The NERRS classification schemes were then applied to the dominant plant species and extent in Zone 1; an area of interest. The method described here classified each polygon to the subclass level and additional information down to the dominant species of each polygon. Zonal statistics were used to calculate emergent vegetation extent at Zone 1 and for a terrestrial area of interest.

NDWI is the ratio of green light reflected to near-infrared absorbed by water. Water absorbs light in the part of the spectrum covered by the Survey $3 \mathrm{~W}$ but tends to absorb much more in the near-infrared, and the ratio between absorption in the green and NIR allows for the delineation of water features [31]. Like NDVI, NDWI values range between -1 and 1 , with values above 0 representing water features and values below 0 representing non-water surfaces. The NDWI equation is:

\section{$\mathrm{NDWI}=\mathrm{B}_{2}-\mathrm{B}_{3} / \mathrm{B}_{2}+\mathrm{B}_{3}$}

where $B_{2}$ is the reflectance at 550-nanometers and $B_{3}$ is the reflectance at 850 -nanometers. NDWI maps were created to calculate the extent of open water during various conditions across multiple scenes. NDWI paired with bathymetric data also allowed for estimates of water volume in the main basin, and when paired with upstream USGS stream discharge data [32] provided estimates of residence time using the available bathymetric data. NDWI values were classified into water and non-water features and visualized to show inundated areas in each scene.

Because water surface elevation cannot be calculated accurately using photogrammetric methods due to the specular nature of the water, and constantly changing angles of the waters surfaces due to water motion, shoreline water levels were found using NDWI values and a 
combined bathymetric and LiDAR dataset. A transect was drawn across the main basin and higher confidence open water pixels are only concentrated at or below the shoreline elevation (Figure 3). This method allowed for shoreline classifications to be calculated for scenes with leaf-off conditions. The shoreline values were validated using a YSI WaterLOG Nile 502 Radar sensor (https://www.ysi.com/Nile) mounted on the bridge at Route 6 and a weather station at Marblehead, $\mathrm{OH}\left(41^{\circ} 32.6^{\prime} \mathrm{N}, 82^{\circ} 43.9^{\prime} \mathrm{W}\right)$ operated by the National Oceanic and Atmospheric Administration (NOAA) [16, 33]. Water volume for the main basin was calculated using the "Surface Volume" toolbox feature in ArcGIS. The shoreline value found was used as a baseline elevation under which a volume was calculated. These volumetric calculations were also compared to previous calculations done by Herdendorf et al. in 1990 [7] [4].

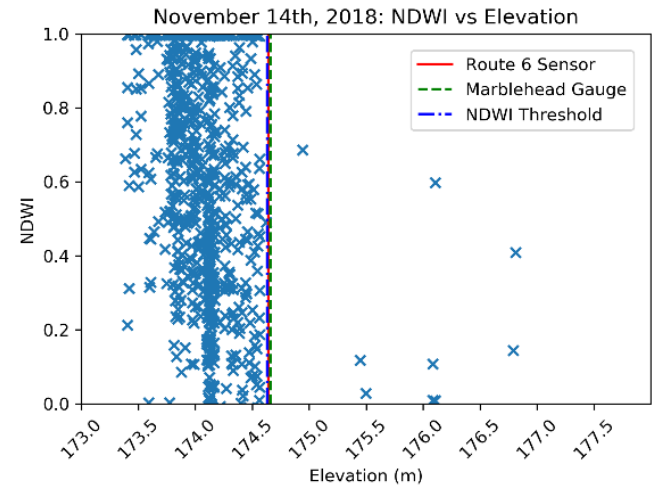

(a)

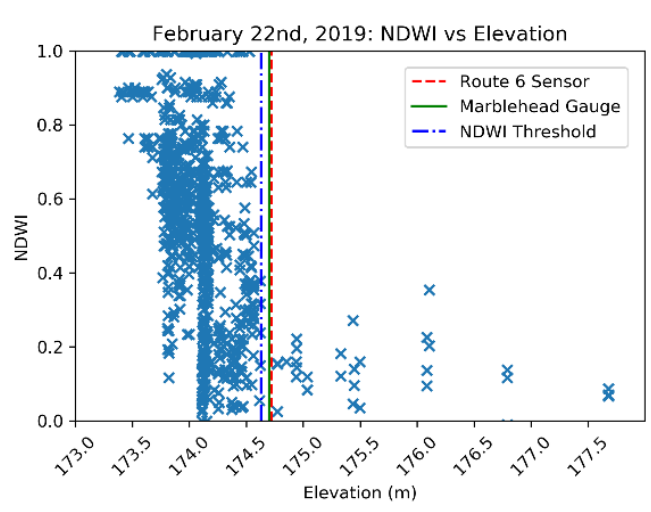

(b)

Figure 3. Open water pixels vs elevation for November $14^{\text {th }}, 2018$ (a) \& February $22^{\text {nd }}, 2019$ (b) with water levels from the microwave sensor on the Route 6 bridge and the gauge at Marblehead.

Residence time for the flowing part of the main basin was also calculated. The flowing part of the basin was identified using turbidity differences. Turbidity increases with sediment transport, which shifts wavelength peaks towards the green [12]. The area of flow volume (V) combined with discharge (Q) values from the USGS streamflow gauge (04199155) [32] upstream from OWC allowed for residence time $(\mathrm{Tr})$ to be calculated using:

$\operatorname{Tr}=\mathrm{V} / \mathrm{Q}$

\section{Results}

\subsection{Flights \& Orthomosaics}

A total of 10 flights were conducted throughout early 2018 to early 2019 [13] (Table 1). Flight times for a single flight averaged between 10-15 minutes for larger areas at about $12 \mathrm{~m} / \mathrm{s}$. Overlap coverage was sufficient both for the Phantom based cameras and the Survey $3 \mathrm{~W}$. The Survey $3 \mathrm{~W}$ was flown using both JPEG and RAW file formats. RAW format pictures take longer for the camera to process and store, and storage space was limited to about 3-4 flights. RAW format pictures did overlap enough for othomosaics and produced high quality orthomosaics, but the higher frequency of JPEG images allowed for more quality control on images which may have experienced significant sunglint or blurring at the cost of data loss due to compression [34].

Table 1. Flight data 


\begin{tabular}{|c|c|c|c|c|}
\hline Date & $\begin{array}{c}\text { Atmospheric } \\
\text { Con ditions }\end{array}$ & Time Flow n & $\begin{array}{c}\text { Vegetation } \\
\text { Conditions }\end{array}$ & $\begin{array}{c}\text { Initial } \\
\text { Images } \\
\text { Acquired }\end{array}$ \\
\hline 10-Apr-18 & Mostly Cloudy & 10AM-12PM & Leaf-Off & 397 \\
\hline 23-Apr-18 & Sunny & 9AM-11AM & Leaf-Off & 1747 \\
\hline 17-May-18 & Sunny & 9AM-12PM & Leaf-On & 1681 \\
\hline 29-May-18 & Sunny & 9AM-11AM & Leaf-On & 448 \\
\hline 28-Sep-18 & Sunny & 9AM-11AM & Mid-Abcission & 1948 \\
\hline 24-Oct-18 & Mostly Cloudy & 10AM-11AM & Mid-Abcission & 735 \\
\hline 25-Oct-18 & Sunny / Hazy & 9AM-11AM & Mid-Abcission & 1631 \\
\hline 30-Oct-18 & Mostly Cloudy & 9AM-11AM & Mid-Abcission & 878 \\
\hline 14-Nov-18 & Mostly Cloudy & 9AM-11AM & Late-Abcission & 642 \\
\hline 22-Feb-19 & Fair & 8AM-11AM & Leaf-Off & 1349 \\
\hline
\end{tabular}

Overlap for both cameras and file formats was sufficient to create the orthomosaics. A total of 16 orthomosaics were created in Agisoft Photoscan, 8 from the RGN Survey $3 \mathrm{~W}$ and 8 from the RGB Phantom cameras [10]. The RGN orthomosaics acquired data with no problems on all flights, and the image overlap was sufficient to create orthomosaics of the study areas of intersest. The RGB camera had acquisition issues on some flights, where the automatic image acquisition was not activated at the start of the flight route. This led to areas of data loss in some scenes. However, analysis was still possible using only the RGN cameras. Other environment issues included variable cloud cover and sunglint (Figure 4). Variable cloud cover led to repeating cloud images on reflective surfaces, namely water. Sunglint resulted in saturation in pixels which had to be masked from images. The high overlap of imagery meant masking some of the more distorting features did not seriously affect the photogrammetric process in most cases.

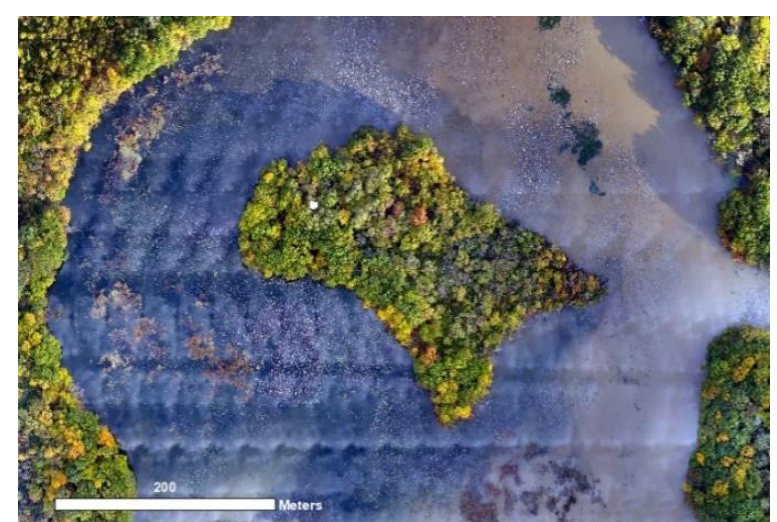

(a)

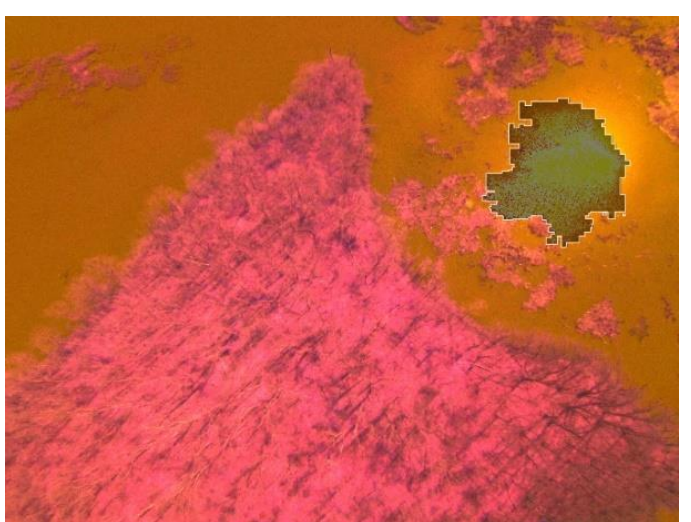

(b)

Figure 4. (a) Variable cloud cover conditions result in a repeating cloud reflection pattern in orthomosaic; (b) Example of sun-glint and applied mask in an RGN photo.

\subsection{Calibration}

The heterogeneous and temporally stable targets used to calibrate the orthomosaics proved sufficient to attain bottom-of-atmosphere reflectances even though the scenes and ASD spectrometer measurements were often temporally different. The root-mean squared and mean absolute error of each orthomosaic scene were calculated to obtain how well each scene calibrated relative to the ASD measurements (Table 2). The RMSE and MAE values reperesent how well the observed surface values used for calibration and validation match the ASD and not necessarily the actual reflectance on the ground. 
Table 2. RMSE and MAE for each orthomosiac.

\begin{tabular}{|c|c|c|c|c|c|c|}
\hline Date & $\begin{array}{c}\text { RMSE } \\
\text { Calibration }\end{array}$ & $\begin{array}{c}\text { RMSE } \\
\text { Validation }\end{array}$ & $\begin{array}{c}\text { RMSE } \\
\text { Combined }\end{array}$ & $\begin{array}{c}\text { MAE } \\
\text { Calibration }\end{array}$ & $\begin{array}{c}\text { MAE } \\
\text { Validation }\end{array}$ & $\begin{array}{c}\text { MAE } \\
\text { Combined }\end{array}$ \\
\hline 23-Apr-18 & 0.051 & 0.038 & 0.044 & 0.042 & 0.030 & 0.035 \\
\hline 17-May-18 & 0.078 & 0.095 & 0.086 & 0.054 & 0.074 & 0.063 \\
\hline 28-Sep-18 & 0.074 & 0.096 & 0.076 & 0.059 & 0.076 & 0.059 \\
\hline 25-Oct-18 & 0.053 & 0.034 & 0.045 & 0.033 & 0.026 & 0.030 \\
\hline 30-Oct-18 & 0.089 & 0.061 & 0.081 & 0.070 & 0.050 & 0.064 \\
\hline 14-Nov-18 & 0.050 & 0.078 & 0.068 & 0.038 & 0.071 & 0.049 \\
\hline 22-Feb-19 & 0.083 & 0.029 & 0.068 & 0.063 & 0.022 & 0.049 \\
\hline
\end{tabular}

\subsection{NDVI}

NDVI values were between -1 and 1 and were classified in different ranges to identify vegetation in 6 NDVI maps. These maps captured the changes in vegetation coverage over the time period of the study and were quantified as percentages above the 0.2 threshold. Vegetation changes were summarized for both emergent vegetation at Zone 1 (Figure 5) and terrestrial vegetation (Table 3) and effectively show the changes in vegetation coverage over time. The spatial resolution of the RGN maps also allowed for shape and texture of individual plants or plant species to be used concurrently with NDVI for classification purposes. Emergent vegetation displayed more dynamic changes throughout the season than terrestrial vegetation.
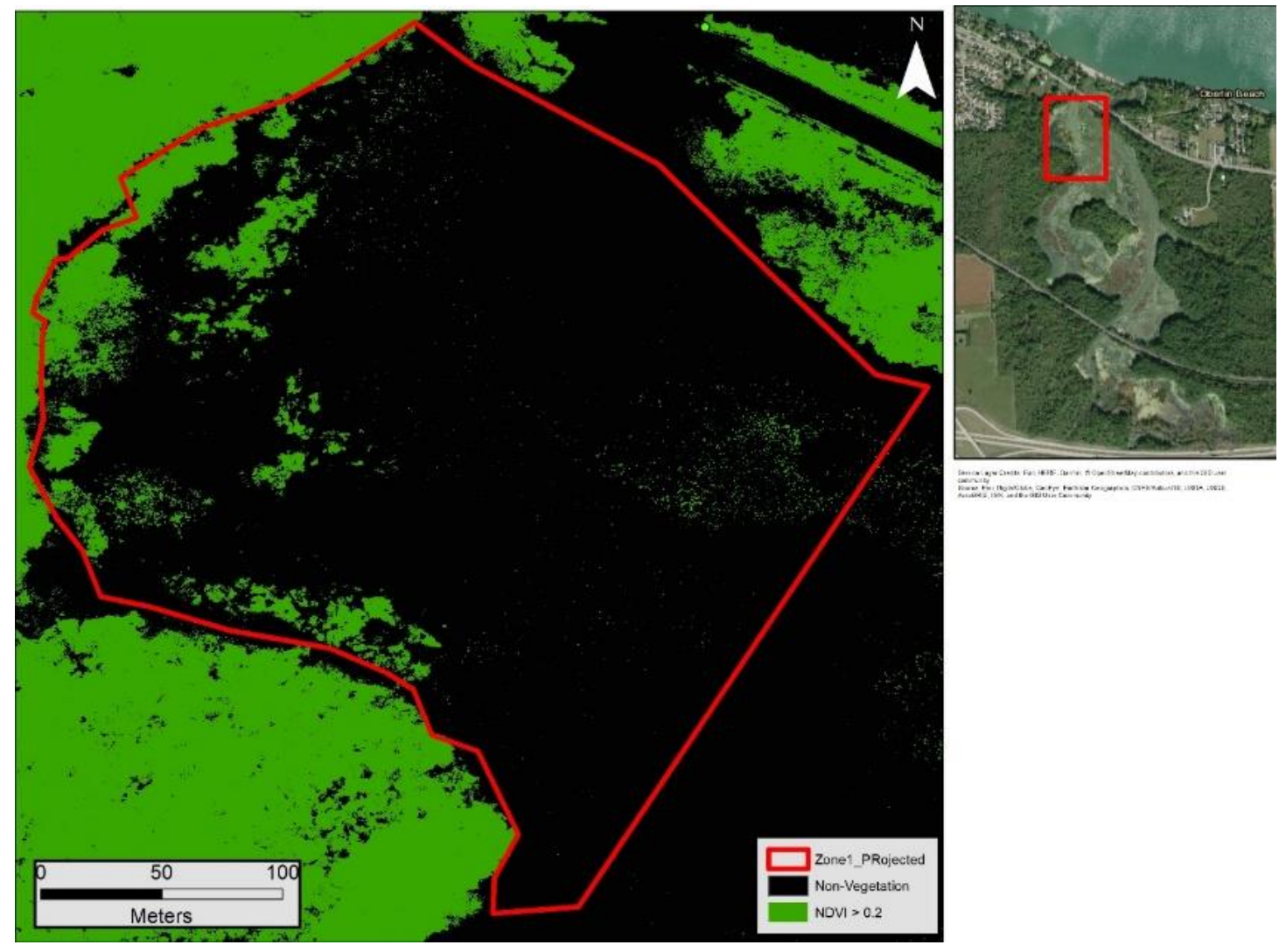

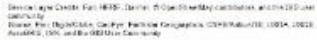

Figure 5. NDVI Zone 1 Analysis on October 25 $5^{\text {th }}, 2018$.

During dense leaf-on conditions there was some saturation in NDVI values, especially in terrestrial settings. Differences in specific values in NDVI are probably not significantly different 
after a certain density of vegetation, such as the difference between 0.5 and 0.7 in a scene [35]. There were also problems in some scenes where both the visible and NIR bands were saturated because the orientation of the sun and the sensor resulting in low NDVI values.

Table 3. Emergent Vegetation NDVI Results at Zone 1 \& Terrestrial Vegetation at an area of interest.

\begin{tabular}{|c|c|c|c|c|c|c|c|c|}
\hline \multicolumn{7}{|c|}{ Zone 1 NDV Statistics } \\
\hline Date & Pixels NDVI $\mathbf{>} \mathbf{0 . 2}$ & Pixel Size $\mathbf{( m )}$ & Pixel Area $\mathbf{( m}^{\mathbf{2}} \mathbf{)}$ & $\begin{array}{c}\text { Vegetation } \\
\text { Area } \mathbf{( m}^{\mathbf{2}} \mathbf{)}\end{array}$ & $\begin{array}{c}\text { Zone 1 } \\
\text { Polygon } \mathbf{( m}^{\mathbf{2}} \mathbf{)}\end{array}$ & Vegetation \% & Mean NDVI & Std Dev \\
\hline 23-Apr-18 & 921,065 & 0.051 & 0.0026 & 2,394 & 56,444 & 4.2 & -0.67 & 0.38 \\
\hline 28-Sep-18 & $16,187,148$ & 0.050 & 0.0025 & 40,477 & 56,444 & 71.7 & 0.30 & 0.15 \\
\hline 25-Oct-18 & $2,178,968$ & 0.046 & 0.0021 & 4,630 & 56,444 & 8.2 & -0.69 & 0.46 \\
\hline 30-Oct-18 & $3,085,460$ & 0.045 & 0.0020 & 6,276 & 56,444 & 11.1 & -0.35 & 0.45 \\
\hline 14-Nov-18 & 530,100 & 0.051 & 0.0026 & 1,370 & 56,444 & 2.4 & -0.47 & 0.36 \\
\hline 22-Feb-19 & 198,569 & 0.048 & 0.0023 & 458 & 56,444 & 0.8 & -0.35 & 0.21 \\
\hline
\end{tabular}

**Note: 17 May displayed significant shift of the red band which did not pass QC checks.

\begin{tabular}{|c|c|c|c|c|c|c|c|c|}
\hline \multicolumn{9}{|c|}{ Terrestrial NDVI Statistics } \\
\hline 23-Apr-18 & $1,882,593$ & 0.0510 & 0.0026 & 4,894 & 5,330 & 91.8 & 0.32 & 0.09 \\
\hline 28-Sep-18 & $1,735,617$ & 0.0500 & 0.0025 & 4,340 & 5,330 & 81.4 & 0.27 & 0.08 \\
\hline 25-Oct-18 & $2,373,334$ & 0.0461 & 0.0021 & 5,043 & 5,330 & 94.6 & 0.37 & 0.10 \\
\hline 22-Feb-19 & $1,169,981$ & 0.0480 & 0.0023 & 2,701 & 5,330 & 50.7 & 0.20 & 0.20 \\
\hline
\end{tabular}

**Note: 17 May displayed significant shift of the red band which did not pass QC checks.

\subsection{NDWI}

NDWI values were between 1 and -1 with values over 0 being open water. The maps produced from NDWI classification created a comprehensive picture of what areas were inundated and what areas were open water (Figure 6). When combined with the validated shoreline data the inundation maps provided a complete picture of which areas were inundated at what water levels. Shoreline water elevations were only created during leaf-off conditions, as during leaf-on conditions the sensor could not detect the water-land boundary. 

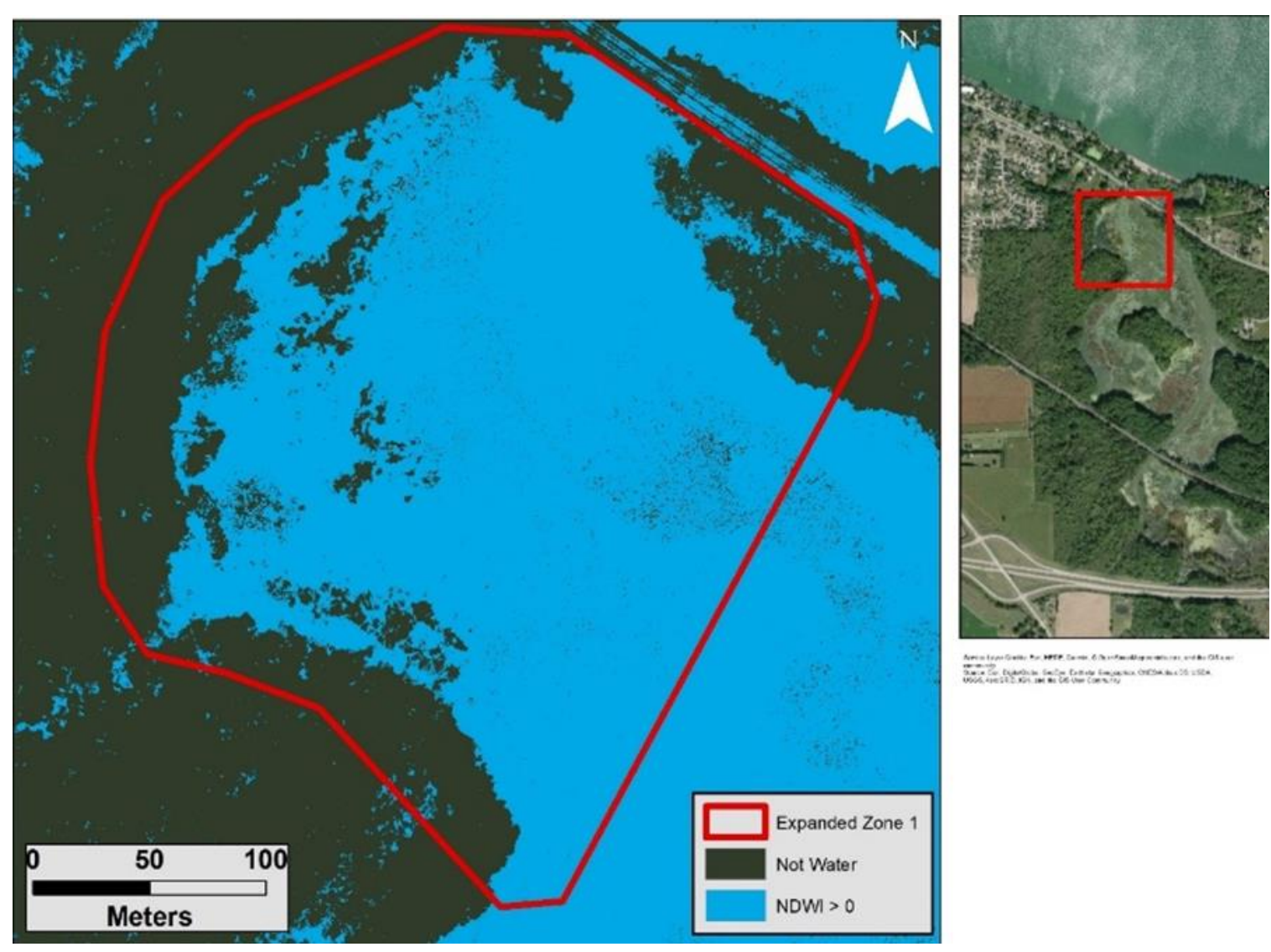

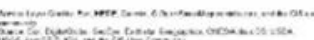

Figure 6. NDWI map at Zone 1 on October $25^{\text {th }}, 2018$.

The 6 NDWI maps (Table 4) produced comprehensive estimates of open water area and provide a comprehensive picture of water inundation, especially in leaf-off and low vegetation conditions. Calculated shorelines generally agreed with the readings from the Route 6 bridge and the NOAA Marblehead water gauge approximately $25 \mathrm{~km}$ northwest of OWC for the three days of leaf-off conditions. During all of these leaf-off days, the beach was open and OWC was hydrologically connected to Lake Erie. Shoreline calculations worked best in areas free of floating debris and overhanging or fallen trees with land-to-water transitions of lower elevation change slopes. The presence of steep bluffs on much of the shoreline make finding gentle slopes visible to the sUAS difficult in the main basin. Pixel sizes for the sUAS imagery ranged from 4.5 to 5.1 centimeters per side.

Table 4. NDWI map results from Zone 1.

\begin{tabular}{|c|c|c|c|c|c|c|c|}
\hline Date & $\begin{array}{c}\text { Open Water } \\
\text { Pixels }\end{array}$ & $\begin{array}{c}\text { Open Water } \\
\text { Area } \mathbf{( m}^{\mathbf{2}} \mathbf{)}\end{array}$ & $\begin{array}{c}\text { Open } \\
\text { Water } \mathbf{( \% )}\end{array}$ & $\begin{array}{c}\text { Bridge Water } \\
\text { Elevation } \mathbf{( m )}\end{array}$ & $\begin{array}{c}\text { sUAS Water } \\
\text { Elevation } \mathbf{( m )}\end{array}$ & $\begin{array}{c}\text { Lake Erie Water } \\
\text { Level (m) }\end{array}$ & $\begin{array}{c}\text { Leaf } \\
\text { Con dtion }\end{array}$ \\
\hline 23-Apr-18 & $21,677,518$ & 56,349 & 68.05 & 174.98 & 174.85 & 174.92 & Off \\
\hline 17-May-18 & $19,447,758$ & 48,622 & 58.72 & 174.98 & NA & 174.96 & On \\
\hline 28-Sep-18 & $11,950,639$ & 29,883 & 36.09 & 175.58 & NA & 174.61 & On \\
\hline 25-Oct-18 & $26,652,148$ & 56,627 & 68.38 & 175.43 & NA & 174.56 & On \\
\hline 30-Oct-18 & $25,602,420$ & 52,075 & 62.89 & 175.72 & NA & 174.63 & On \\
\hline 14-Nov-18 & $22,059,928$ & 57,032 & 68.87 & 174.64 & 174.63 & 174.66 & Off \\
\hline 22-Feb-19 & $25,688,115$ & 59,297 & 71.61 & 174.72 & 174.63 & 174.70 & Off \\
\hline
\end{tabular}

When comparing the volumetric and residence time calculations (Table 5) from the sUAS and those done by Herdendorf et al. in 1990, the newer bathymetric survey should be a more accurate measure of the present day depths along the basin, although it was incomplete at the time of this publication. The bathymetric survey which was used for this study does not cover 
approximately 56,133 $\mathrm{m}^{2}$ (13.9 acres) of the southwestern side of Star Island. Differences may also be the result of changes to the bottom of the estuary between 1990 and 2019.

Table 5. Volume \& Residence Time Comparisons.

\begin{tabular}{|c|c|c|c|c|c|c|c|c|}
\hline Date & $\begin{array}{c}\text { sUAS } \\
\text { Water } \\
\text { Elevation } \\
\text { (NAVD 88) }\end{array}$ & $\begin{array}{c}\text { sUAS Volume: } \\
\text { Main Basin } \\
\left(\mathbf{m}^{\mathbf{3}}\right)\end{array}$ & $\begin{array}{c}\text { USGS } \\
\text { Discharge } \\
\left(\mathbf{m}^{\mathbf{3}} \mathbf{/ s}\right)\end{array}$ & $\begin{array}{c}\text { sUAS Residence } \\
\text { Time: Main } \\
\text { Basin (days) }\end{array}$ & $\begin{array}{c}\text { Channel } \\
\text { Volume } \\
\left(\mathbf{m}^{\mathbf{3}}\right)\end{array}$ & $\begin{array}{c}\text { Channel } \\
\text { Residence } \\
\text { Time (Days) }\end{array}$ & $\begin{array}{c}\mathbf{1 9 9 0} \text { Survey } \\
\text { Water Volume } \\
\left(\mathbf{m}^{\mathbf{3}}\right)\end{array}$ & $\begin{array}{c}\text { Basin \% Difference } \\
\mathbf{( 1 9 9 0} \mathbf{v s} \text { sUAS) }\end{array}$ \\
\hline 23-Apr-18 & 174.85 & 318,168 & 0.317 & 12 & 144,295 & 5 & 350,000 & 9.1 \\
\hline 14-Nov-18 & 174.63 & 231,121 & 0.595 & 4 & 110,772 & 2 & 245,000 & 5.7 \\
\hline 22-Feb-19 & 174.63 & 231,121 & 1.17 & 2 & 110,772 & 1 & 245,000 & 5.7 \\
\hline
\end{tabular}

\subsection{Classification \& Analysis}

A manual classification was used to identify vegetation habitats and species. NDVI was used to identify spectral differences and stages of senescence in plant species, and the high-resolution of the datasets allowed for texture and spatial shapes to be used as well (Figure 7a). The different classifications were separated by polygons and the spatial extent of each was extracted (Figure $7 \mathrm{~b}$ ).

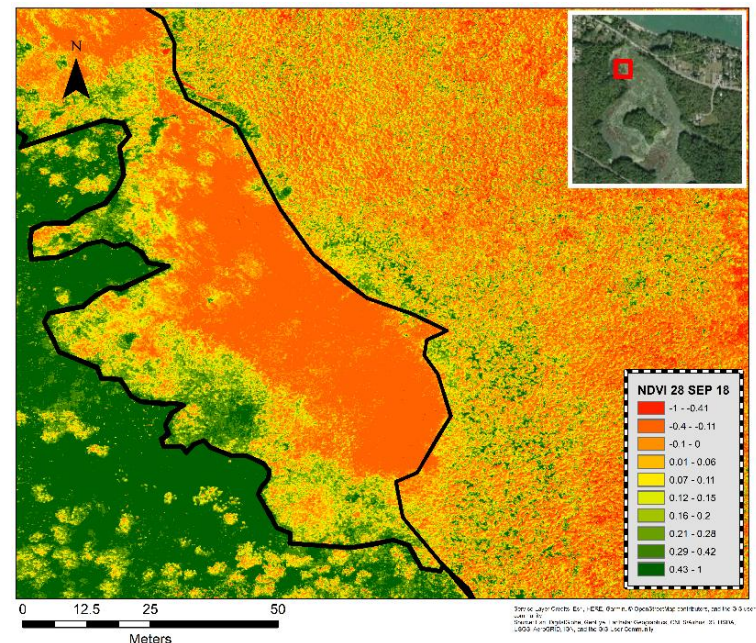

(a)

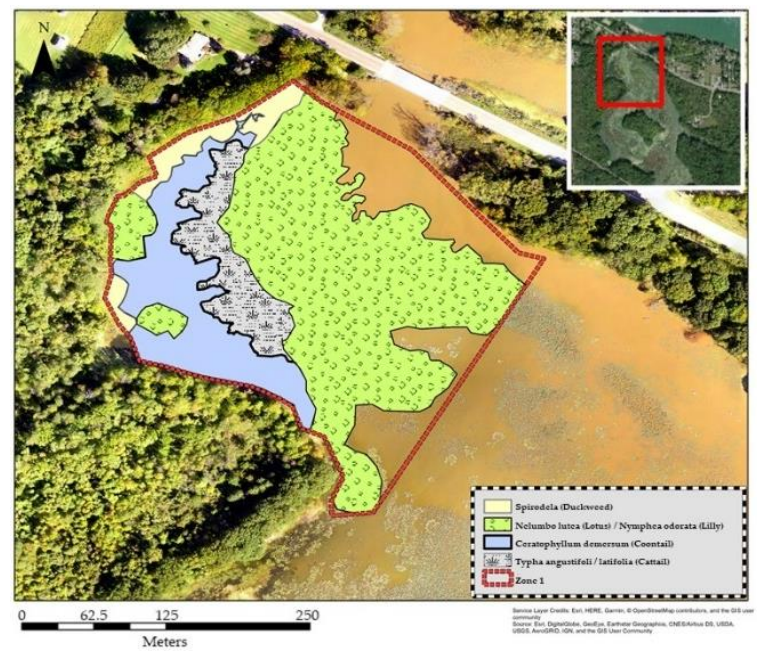

(b)

Figure 7. (a) Spectral and spatial differences between dominant species in a subsection of Zone 1; (b) Manual classifications resulting in dominant species polygons in Zone 1.

The quantified areas of each dominant species type were compared across scenes to obtain changes in vegetation coverage over time. Ceratophyllum, a submergent vegetation species, was detected on September $28^{\text {th }}$, but was completely undetectable on October $25^{\text {th }}$. This may be due to differences in sun angle and brightness between both dates which resulted in greater light penetration and greater reflection of Ceratophyllum from beneath the water surface.

Table 7. Vegetation extent changes over time from September to October. 


\begin{tabular}{|l|c|c|}
\hline \multicolumn{3}{|c|}{ September $\mathbf{2 8 t h}$} \\
\hline \multicolumn{1}{|c|}{ Type } & Area $\left.\mathbf{( m}^{\mathbf{2}}\right)$ & $\mathbf{\%}$ (Zone $\mathbf{1})$ \\
\hline Spirodela & 2,635 & 5 \\
\hline Ceratophyllum & 9,984 & 18 \\
\hline Typha & 5,129 & 9 \\
\hline Nelumbo Lutea & 29,650 & 53 \\
\hline Open Water & 9,046 & 16 \\
\hline Zone 1 Total & 56,444 & \\
\hline
\end{tabular}

\begin{tabular}{|l|c|c|}
\hline \multicolumn{3}{|c|}{ October 25th } \\
\hline \multicolumn{1}{|c|}{ Type } & Area $\left.\mathbf{( m}^{\mathbf{2}}\right)$ & $\mathbf{\%}$ (Zone $\mathbf{1})$ \\
\hline Spirodela & 4,185 & 7 \\
\hline Ceratophyllum & 0 & 0 \\
\hline Typha & 1,667 & 3 \\
\hline Nelumbo Lutea & 27,430 & 49 \\
\hline Open Water & 23,161 & 41 \\
\hline Zone 1 Total & 56,444 & \\
\hline
\end{tabular}

The polygons of dominant plant species was also used to satisfy the requirements of the NERRS classification system. The polygons were numbered (Figure 8 ) and a table of habitat classifications was produced (Table 8).

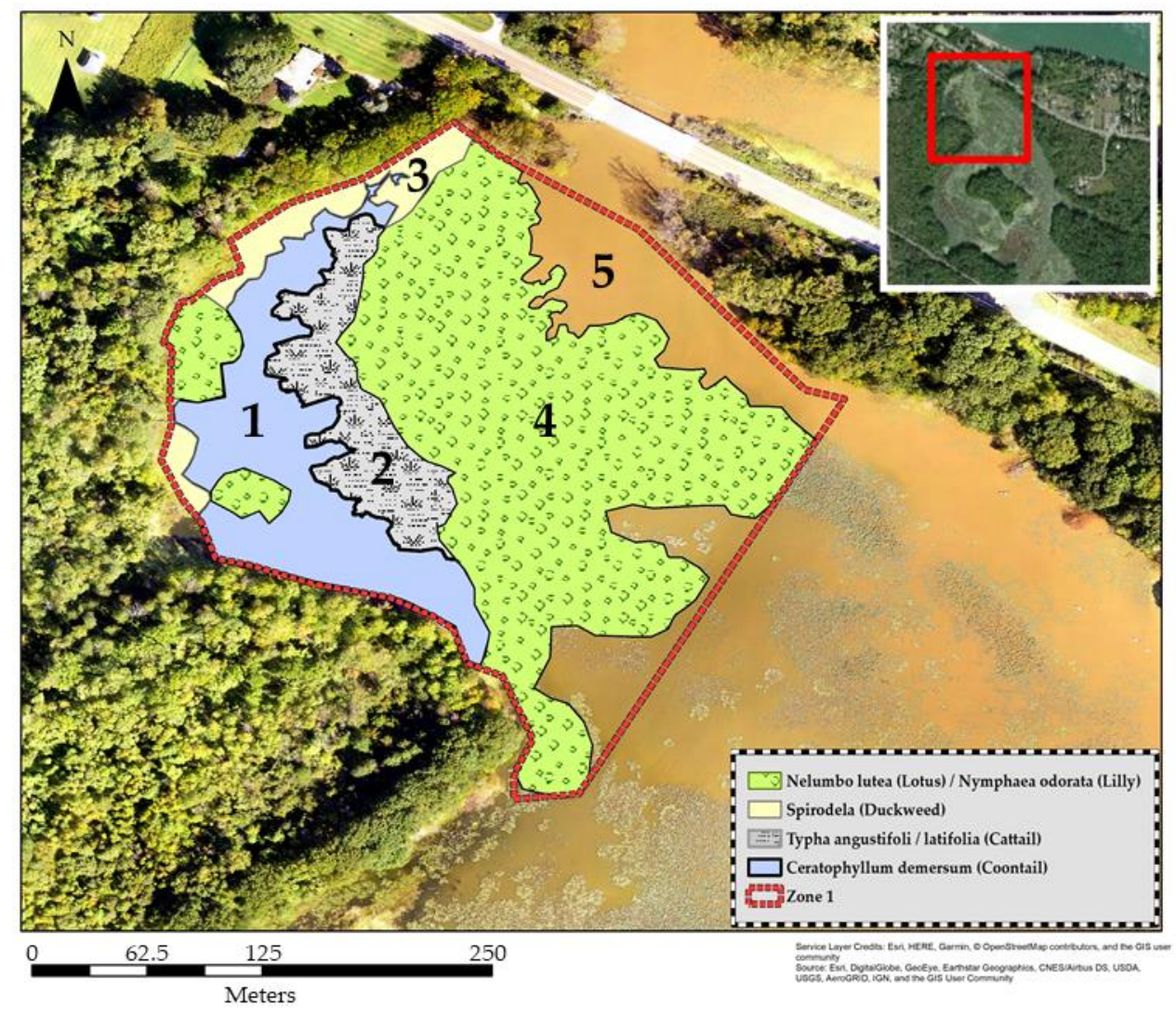

Figure 8. NERRS Classification polygons.

The RGN and RGB orthomosaics were of high enough quality to satisfy the NERRS classification schemes at least to the subclass level and dominant species type could be appended to the table (Table 8). Similar maps could easily be used to satisfy periodic surveys of habitat changes over time for wetland managers at a higher temporal resolution than is currently available. The dominant species of these polygons was validated by volunteers and ecologists at OWC by boat.

Table 8. Vegetation extent changes over time from September to October. 
12 of 18

\begin{tabular}{|l|c|c|c|c|c|c|}
\hline Polygon & System & Subsystem & Class & Subclass & $\begin{array}{c}\text { NERRS } \\
\text { Code }\end{array}$ & Dominant Species \\
\hline Polygon 1 & Estuarine & Subtidal Fresh & Aquatic Bed & Floating Vascular & 2400 & Ceratophyllum demersum \\
\hline Polygon 2 & Estuarine & Subtidal Fresh & Emergent Wetland & Persistent & 2400 & Typha angustifoli / latifolia \\
\hline Polygon 3 & Estuarine & Subtidal Fresh & Emergent Wetland & Floating Vascular & 2400 & Spirodela polyrhiza \\
\hline Polygon 4 & Estuarine & Subtidal Fresh & Emergent Wetland & Rooted Vascular & 2400 & Nelumbo lutea \\
\hline Polygon 5 & Estuarine & Subtidal Fresh & Emergent Wetland & Unconsolidated Bottom & 5100 & None \\
\hline
\end{tabular}

\subsection{Satellite E Aerial Platform Comparison}

The Survey 3W camera provided a higher resolution product than available satellite or aerial imagery (Figure 9). The water-land boundary was much more easily distinguished and the sUAS proved to be a more flexible solution only limited by weather and batteries.

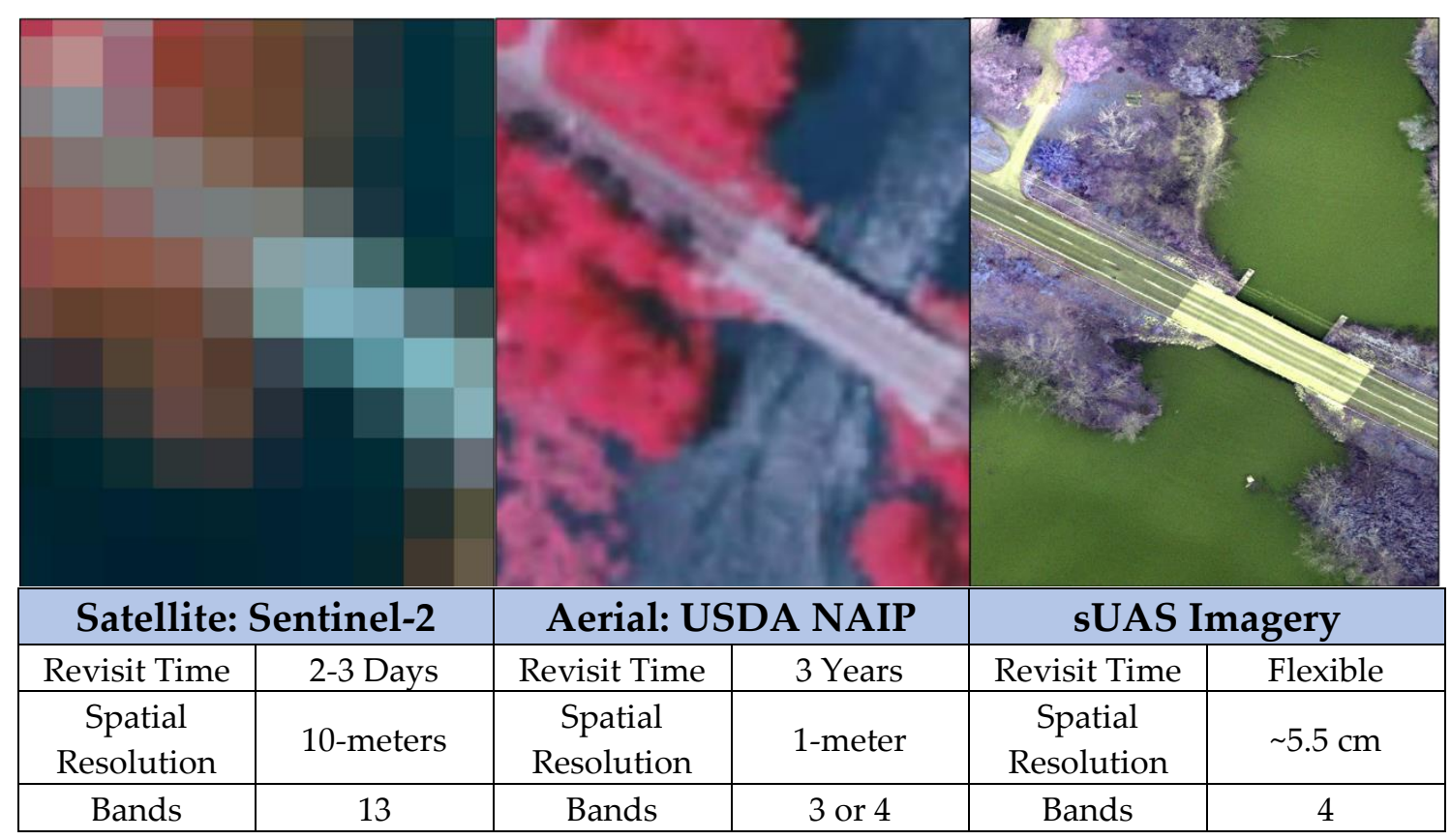

Figure 9. Survey $3 \mathrm{~W}$ comparison to Sentinel-2 and NAIP imagery.

The higher spatial resolution of the Survey $3 \mathrm{~W}$ means a reduction in pixel mixing compared to satellite and aerial imagery. Especially in satellite imagery, pixel mixing means an inability to distinguish finer features in a scene and an averaging of brightness values across a single pixel [2]. The Survey $3 \mathrm{~W}$ produced much more comprehensive distinctions between not only the water-land boundaries, but water-vegetation boundaries when vegetation canopy was larger than $25 \mathrm{~cm}^{2}$ and resulted in much more accurate extent measurements for areas of interest.

Sentinel-2 from dates close to the sUAS flights showed a consistent overestimation of emergent vegetation in Zone 1 due to pixel mixing (Figure 10a). NAIP imagery was not available for the dates the sUAS flew as it is only flown every 2-3 years, but the latest flights from 2017 show similar but slightly lower spatial resolution. In the terrestrial area of interest for the same dates, Sentinel-2 displayed a 100\% vegetation detection due to mixed pixels, whereas the Survey $3 \mathrm{~W}$ was able to distinguish between different NDVI values in the same area (Figure 10b). 


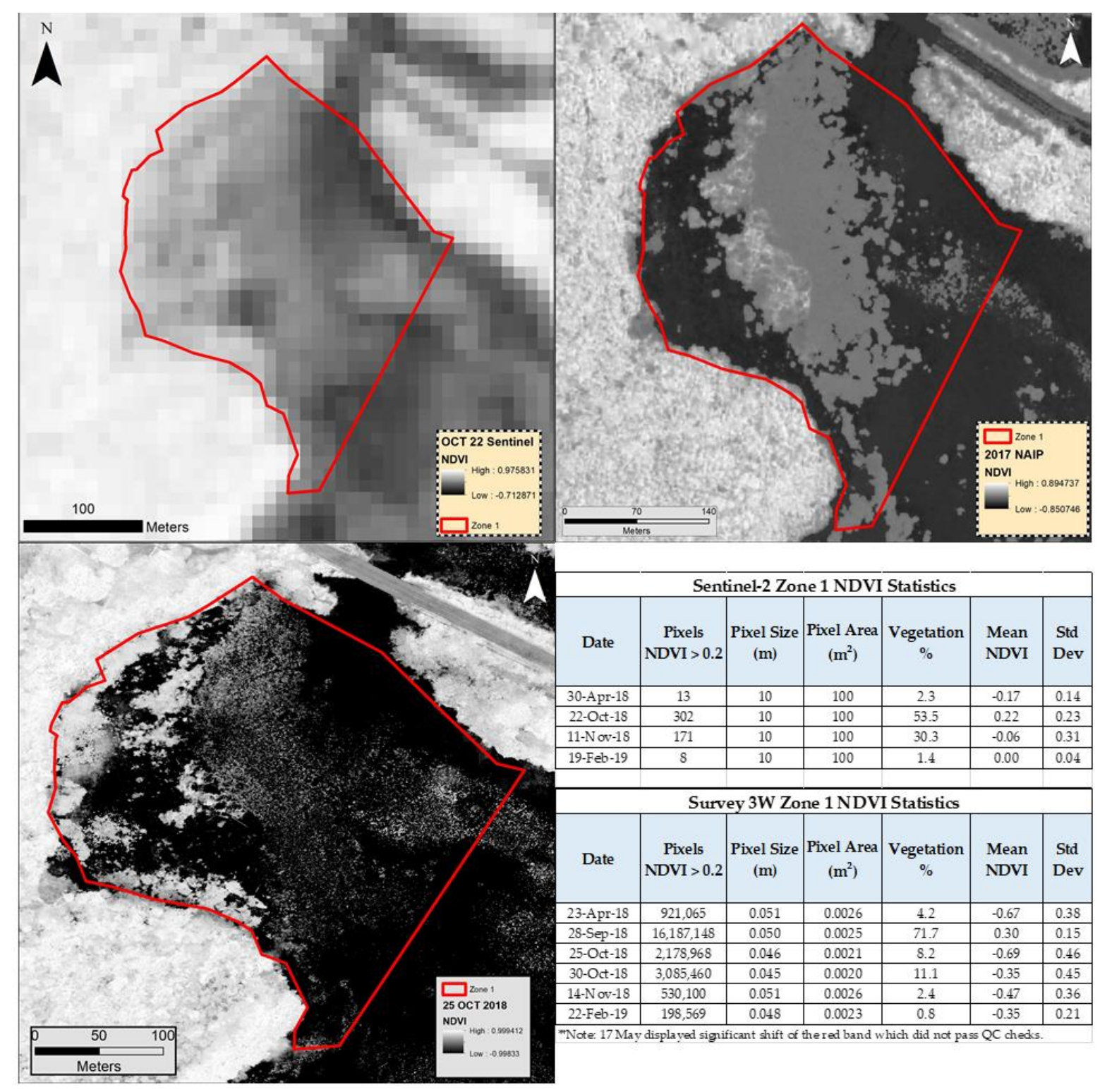

(a) 


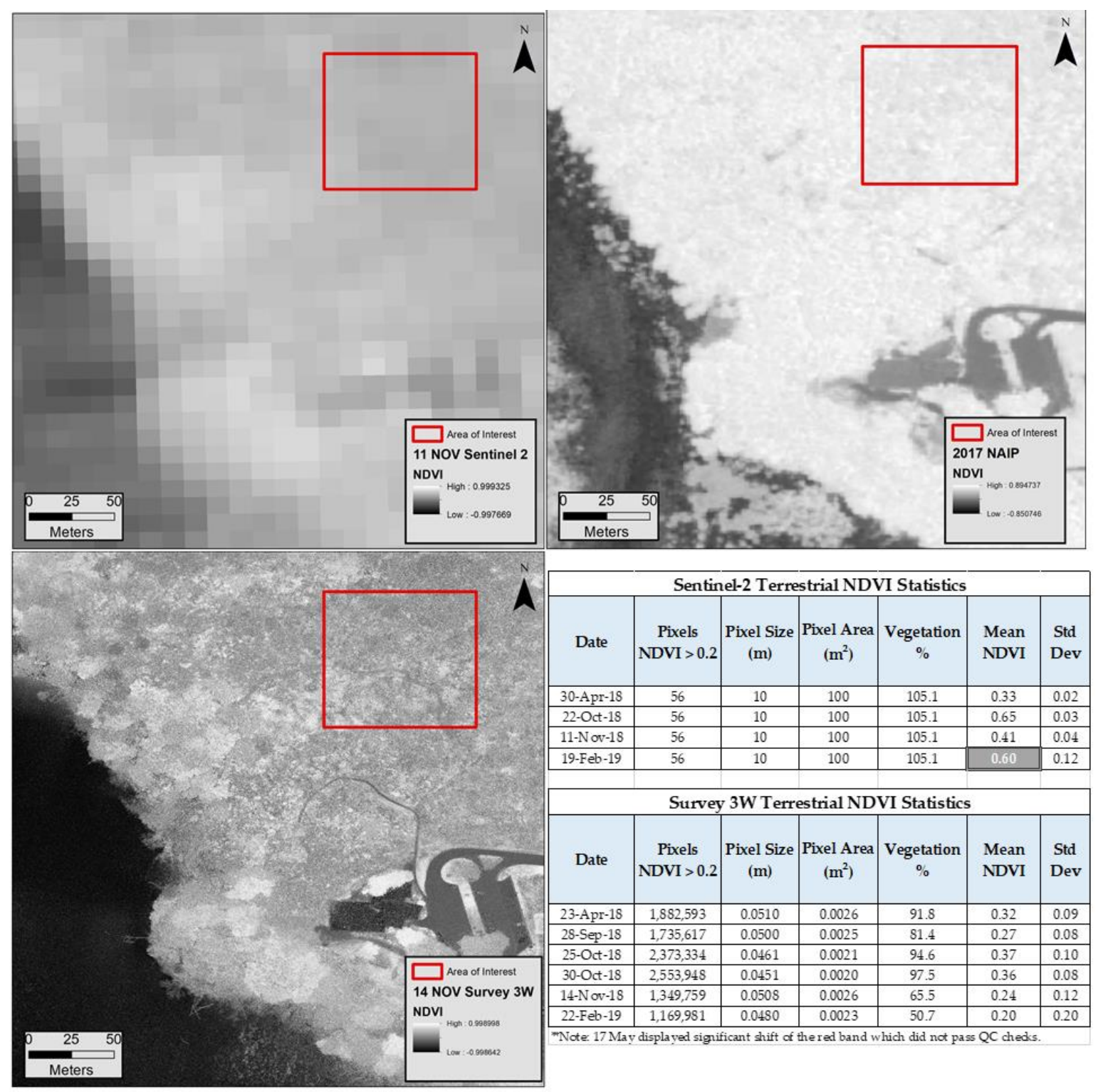

(b)

Figure 10. (a) Comparison of Survey 3W, Sentinel-2, and NAIP imagery at Zone 1; (b) Comparison of Survey $3 \mathrm{~W}$, Sentinel-2, and NAIP imagery at a terrestrial area of interest.

NDWI comparisons similarly show much better distinctions between water and non-water surfaces with the Survey $3 \mathrm{~W}$. Sentinel-2 tended to underestimate the area of open water due to pixel mixing, and NAIP imagery, although of similar spatial resolution, was not available for the time period of the study.

\section{Discussion}

The methods used in this study for planning and conducting flights would be easily implemented at other wetland areas. The main challenges were planning flights around visitors and finding suitable takeoff sites. Flights in this study were limited to the morning hours when foot traffic was low. There were also potential takeoff sites in the southern part of the estuary, but they were difficult to get to and during most of the year there was dense canopy making takeoff options limited. Weather conditions, FAA Part 107 regulations, and non-interference with wildlife are considerations which must be addressed by the pilot-in-command before each flight. 
Sun-glint and saturation were the main spectral factors which affected the orthomosaic process. Sun-glint is a result of the reflected light of water surfaces at an angle at which they are pointed directly at the Survey $3 \mathrm{~W}$ sensor [36]. All flights were conducted at about the same time of day, but the angle of the flight legs was changed for some flight as an attempt to limit sun-glint. Most flights had enough images with sufficient overlap that masking out the sun glint was not a problem regardless of flight directions, but previous studies suggest the camera be positioned $40^{\circ}$ from nadir vertically and $135^{\circ}$ horizontally from the sun to minimize sun-glint [37]. The flexibility and repeatability of the sUAS allows for more data to be collected quickly and easily if sun-glint or saturation is too pronounced on a single flight.

One great advantage of sUAS flights is the ability to collect data on cloudy days. The sUAS was able to fly on cloudy days and collect relevant data, especially when limited to vegetation or water extent with less consideration for density and health measurements. However, with this advantage comes the considerations and challenges with flying under cloud cover. For instance, cloud reflections on water proved difficult for the orthomosaic software. A flight on October 30 th was flown under variable cloud cover shortly before the barrier beach was breached, and although vegetation coverage was preserved, variable cloud cover could be seen clearly in the orthomosaics of both the RGN and RGB scenes. NDWI values for this day resulted in inaccurate pixel classifications. In addition, the intermittent cloud cover resulted in a "flashlight" effect where part of the scene was much brighter than the surrounding flights.
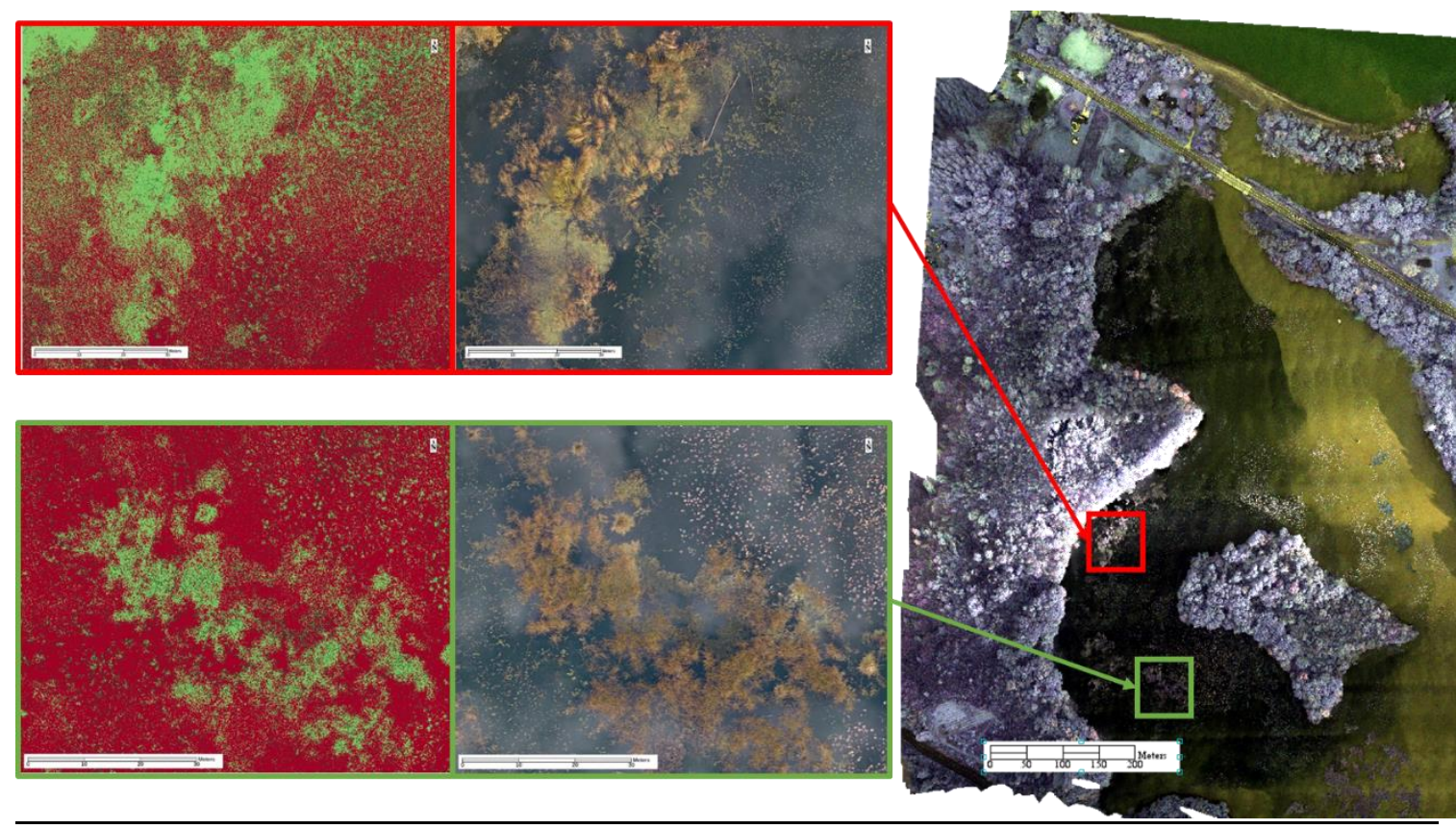

Figure 11. Flight on October $30^{\text {th }}, 2018$ under variable cloud cover which displayed some orthomosaic anomalies to include repeating cloud patterns and a flashlight effect.

The horizontal and vertical accuracy of the orthomosaics in this study could be improved in future studies. OWC is a homogeneously textured area resulting in a lack of tie points in forested areas. The density of the forested canopy resulted in a lack of places to put GCPs. One study suggests placing a GCP every 100 meters in any direction [38], while another suggests a GCP for every $200 \mathrm{~m}^{2}$ [39] to prevent distortions. Increasing the positional accuracy of the orthomosaics would allow for volumetric calculations to be done with point cloud software with volumetric change calculation functions, especially if the GCPs were placed strategically around the submerged parts of the basin. OWC could install permanent or semi-permanent indicators on stable surfaces to use in continual surveys, as long as the GCPs were large enough to be seen clearly from the sensors. 


\section{Conclusions}

SUAS offer a method for monitoring wetland systems which is relatively inexpensive, accurate, and versatile. With the Survey $3 \mathrm{~W}$ or a similar sensor, NDWI can detect the extent of open water and inundation while NDVI can assess vegetation extent. In a managed reserve or park, routine ground validation can be done with no extra effort on the part of staff and volunteers, and the addition of high-resolution remote sensing data can vastly increase the understanding of local hydrologic processes and vegetation habitat changes. The data shown here has been shown to be sufficient to satisfy the requirements of the NERRS classification system for use in habitat monitoring over time.

The cost of the sUAS platform is much more attainable to wetland managers than aerial imagery, with the entire system costing about $\$ 1,500$ in addition to calibration targets which range from $\$ 300$ $\$ 2,000$. The same software used for this project could also be used for aerial and satellite imagery, but many additional options are becoming available with the proliferation of sUAS and miniaturized remote sensing technology. The sUAS method described here, when compared to Sentinel-2 and NAIP data, is higher resolution and offers more flexibility and control in its application.

SUAS applications offer a way to map wetland changes and monitor how these changes affect the habitat of plant and animal life over time. This method allows users to collect data in their areas of interest whenever they need it instead of requiring data from other remote sensing platforms which may or may not be available.

Supplementary Materials: For a more in-depth discussion of the method used here, please visit OhioLINK (http://rave.ohiolink.edu/etdc/view?acc_num=toledo1556713788128588)

Author Contributions: Richard Becker and Dustin Dehm conceived and designed the research, conducted the UAV flights and data acquisition, and analyzed the data. Dustin Dehm and Alexandra Godre acquired field bathymetric and vegetation data. Dustin Dehm wrote the manuscript. Richard Becker and Alexandra Godre helped with editorial contributions.

Funding: This research was funded by NOAA through the NEERS program.

Acknowledgments: Thank you to the staff at Old Woman Creek National Estuarine Research Reserve for their support, especially Dr. Kristin Arend and Breann Hohman. Their dedication and willingness to promote scientific research on their property and to lend assistance whenever possible was of untold importance to this and many other projects. We'd also like to express gratitude for the visual observers who helped to monitor the drone in flight to include: Alexandra Godre, Eric Armstrong, Thomas Valachovics, Brian Samsen, Alex Sodeman and Sarah McGuinness. Thank you also to the volunteers at OWC for helping to validate our vegetation data.

Conflicts of Interest: The authors declare no conflict of interest.

\section{References}

1. ESA. Sentinel Online. [Website] 201720174 December 2017]; Available from: https://sentinel.esa.int/web/sentinel/missions/sentinel-2/data-products.

2. Frazier, P.S. and K.J. Page, Water body detection and delineation with Landsat TM data. Photogrammetric engineering and remote sensing, 2000. 66(12): p. 1461-1468.

3. Knoth, C., et al., Unmanned aerial vehicles as innovative remote sensing platforms for high-resolution infrared imagery to support restoration monitoring in cut-over bogs. Applied Vegetation Science, 2013. 16(3): p. 509517.

4. Herdendorf, C., D.M. Klarer, and R.C. Herdendorf, The Ecology of Old Woman Creek, Ohio: An Esturine and Watershed Profile. 2004: Ohio Department of Natural Resources.

5. Tomaszek, J.A., W.S. Gardner, and T.H. Johengen, Denitrification in sediments of a Lake Erie coastal wetland (Old Woman Creek, Huron, Ohio, USA). Journal of Great Lakes Research, 1997. 23(4): p. 403-415.

6. Albert, D.A., et al., Hydrogeomorphic classification for Great Lakes coastal wetlands. Journal of Great Lakes Research, 2005. 31: p. 129-146. 
7. Herdendorf, C.E., Great lakes estuaries. Estuaries and Coasts, 1990. 13(4): p. 493-503.

8. Mouw, C.B., et al., Aquatic color radiometry remote sensing of coastal and inland waters: Challenges and recommendations for future satellite missions. Remote Sensing of Environment, 2015. 160: p. 15-30.

9. Hardin, P.J. and T.J. Hardin, Small-Scale Remotely Piloted Vehicles in Environmental Research. Geography Compass, 2010. 4(9): p. 1297-1311.

10. Dehm, D., A Small Unmanned Aerial System (sUAS) Based Method for Monitoring Wetland Inundation E Vegetation, in Department of Environmental Sciences. 2019, University of Toledo: Toledo, OH. p. 120.

11. DJI, Phantom 4 Pro. 2018, Dà-Jiāng Innovations

12. Campbell, J.B. and R.H. Wynne, Introduction to remote sensing. 2011: Guilford Press.

13. FAA. Part 107 - Small Unmanned Aircraft Systems. Title 14: Aeronautics \& Space 2018 January 9, 2018 [cited 2018 January 11, 2018]; Available from: https://www.ecfr.gov/cgi-bin/text$\underline{\mathrm{idx}}$ ?SID=c0d353fab27e306b532c17cd290b59e8\&mc=true\&node=pt14.2.107\&rgn=div5.

14. Gini, R., et al., UAV photogrammetry: Block triangulation comparisons. Int. Arch. Photogram. Remote Sens. Spat. Inf. Sci, 2013. 1: p. W2.

15. MAPIR. Survey 3W Camera - Red+Green+NIR (RGN, NDVI). 2018 [cited 2018; Available from: https://www.mapir.camera/products/survey3w-camera-red-green-nir-rgn-ndvi.

16. NGS. NAVD88 - IGLD85 Height Conversion. [Web Page] 2017 May 16, 2017 November 2018]; Available from: https://www.ngs.noaa.gov/TOOLS/IGLD85/igld85.shtml.

17. Barrand, N.E., et al., Optimizing photogrammetric DEMs for glacier volume change assessment using laserscanning derived ground-control points. Journal of Glaciology, 2009. 55(189): p. 106-116.

18. Becker, R.H., K.A. Zmijewski, and T. Crail, Seeing the forest for the invasives: mapping buckthorn in the Oak Openings. Biological Invasions, 2013. 15(2): p. 315-326.

19. Clark, B., J. Suomalainen, and P. Pellikka, The selection of appropriate spectrally bright pseudo-invariant ground targets for use in empirical line calibration of SPOT satellite imagery. ISPRS journal of photogrammetry and remote sensing, 2011. 66(4): p. 429-445.

20. Moore, T.S., et al., Bio-optical Properties of Cyanobacteria Blooms in Western Lake Erie. Frontiers in Marine Science, 2017. 4: p. 300.

21. Agisoft, L., Agisoft Photoscan Professional (Version 1.4.2) (Software). Professional Edition, 2018.

22. Westoby, M., et al., 'Structure-from-Motion'photogrammetry: A low-cost, effective tool for geoscience applications. Geomorphology, 2012. 179: p. 300-314.

23. Henriques, M.J., et al., Assessing the Quality of an UAV-based Orthomosaic and Surface Model of a Breakwater. 2014.

24. NUPO. Agisoft PhotoScan Workflow. [PDF] 2017 March 2017 [cited 2018 June 1st]; USGS Agisoft $\begin{array}{llll}\text { Photoscan } & \text { for UASlow } & \text { Available }\end{array}$ https://uas.usgs.gov/nupo/pdf/USGSAgisoftPhotoScanWorkflow.pdf.

25. Granshaw, S.I., Photogrammetric Terminology: Third Edition. The Photogrammetric Record, 2016. 31(154): p. 210-252.

26. McLauchlan, P.F. and A. Jaenicke, Image mosaicing using sequential bundle adjustment. Image and Vision Computing, 2002. 20(9): p. 751-759.

27. Smith, G.M. and E.J. Milton, The use of the empirical line method to calibrate remotely sensed data to reflectance. International Journal of remote sensing, 1999. 20(13): p. 2653-2662. 
28. Farrand, W.H., R.B. Singer, and E. Merényi, Retrieval of apparent surface reflectance from AVIRIS data: A comparison of empirical line, radiative transfer, and spectral mixture methods. Remote Sensing of Environment, 1994. 47(3): p. 311-321.

29. Rouse Jr, J.W., et al., Monitoring vegetation systems in the Great Plains with ERTS. 1974.

30. USGS. NDVI, The Foundation for Remote Sensing Phenology. Vegetation Indices [Webpage] 2015 1/12/2015 [cited 2018 1/25/2018]; Available from: https://phenology.cr.usgs.gov/ndvi foundation.php.

31. McFeeters, S.K., The use of the Normalized Difference Water Index (NDWI) in the delineation of open water features. International journal of remote sensing, 1996. 17(7): p. 1425-1432.

32. USGS, USGS 04199155 Old Woman Creek at Berlin Rd near Huron, OH. 2018, U.S. Geological Survey.

33. Service, N.N.O., Tides \& Currents. 2019, Center for Operational Oceanographic Products and Services

34. Verhoeven, G., It's all about the format-unleashing the power of RAW aerial photography. International Journal of Remote Sensing, 2010. 31(8): p. 2009-2042.

35. Huete, A.R., H. Liu, and W.J. van Leeuwen. The use of vegetation indices in forested regions: issues of linearity and saturation. in Geoscience and Remote Sensing, 1997. IGARSS'97. Remote Sensing-A Scientific Vision for Sustainable Development., 1997 IEEE International. 1997. IEEE.

36. Kay, S., J. Hedley, and S. Lavender, Sun glint correction of high and low spatial resolution images of aquatic scenes: a review of methods for visible and near-infrared wavelengths. Remote sensing, 2009. 1(4): p. 697-730.

37. Mobley, C.D., Estimation of the remote-sensing reflectance from above-surface measurements. Applied optics, 1999. 38(36): p. 7442-7455.

38. Tonkin, T. and N. Midgley, Ground-control networks for image based surface reconstruction: An investigation of optimum survey designs using UAV derived imagery and structure-from-motion photogrammetry. Remote Sensing, 2016. 8(9): p. 786.

39. Oniga, V.-E., A.-I. Breaban, and F. Statescu. Determining the optimum number of ground control points for obtaining high precision results based on UAS images. in Multidisciplinary Digital Publishing Institute Proceedings. 2018. 